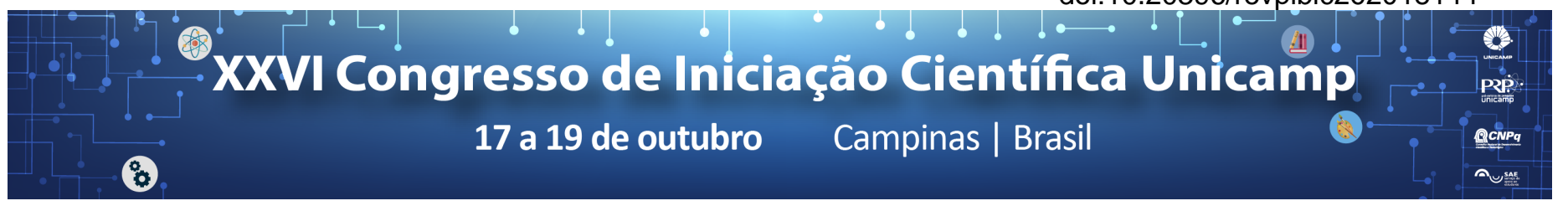

\title{
A Relação Entre a Musica de Joe Hisaishi e a Direção de Hayo Miyazaki
}

\author{
André E. R. Silva, Carolina Morgado Leão
}

\begin{abstract}
Resumo
A pesquisa analisou a relação da música de Joe Hisaishi no filme Mononoke Hime do diretor Hayao Miyazaki. Para esse entendimento buscou-se compreender a parceria de anos desses dois artistas. A partir disso foi escrito uma breve bibliografia de ambos. Houve um levantamento bibliográfico de analises do filme Mononoke Hime, assim foi possível ter um melhor entendimento tanto da proposta do filme quanto de possíveis motivações para a sua composição. Durante a pesquisa, se averiguou ao decorrer do filme a existência do conceito Ma, forma em que a cultura japonesa compreende o silencio, tempo e espaço entre objetos e ações. Buscou-se então bibliograficas dedicadas a esse tema para uma melhor compreensão, e então uma analise da articulação do som e da imagem junto com o pensamento do Ma.
\end{abstract}

\section{Palavras-chave:}

Joe Hisaishi, Hayao Miyazaki, Mononoke Hime

\section{Introdução}

O estúdio de animação japonês Studio Ghibli contem características marcantes, é possível reconhecer suas produções sem dificuldade alguma. Portanto, por ser um estúdio impar dentro do mercado japonês, foi escolhido como objeto de estudo o longa-metragem Mononoke Hime (1997), de direção de Hayao Miyazaki e trilha sonora de Joe Hisaishi. Este filme foi o primeiro grande sucesso de bilheteria internacional do Studio Ghibli, e é uma das obras de Miyazaki com mais relevância em sua carreira.

Mononoke Hime é um dos últimos filmes da atualidade feito em sua maioria com celuloide, e com pouca utilização do computador na sua construção. Foi criado em um momento em que o produtor do Studio Ghibli Toshio Suzuki disse que a equipe de desenhistas estava mais preparada.

Tratando de forma crítica temas como ecologia e questões gênero, o longa-metragem mostra os impactos de uma industrialização na natureza e uma sociedade na qual as mulheres possuem poder e liberdade. No âmbito técnico Miyazaki traz o silêncio através de pausas e contemplações sem perder o ritmo de um filme de ação, utilizando do conceito japonês Ma.

Ambientada no Japão, Hisaishi compõe uma trilha musical que compactua com o local, utilizando instrumentos e escalas musicais tradicionais japonesas, além de uma orquestra completa. Sobre esse trabalho Hisaishi diz "Eu queria expressar seus sentimentos (Miyazaki) através da música. Nas músicas que fiz no passado tentei me aproximar dos sentimentos do público e do ambiente da tela".

Portanto, devido sua importância e singularidade, buscou-se uma compreensão de como a trilha sonora de Joe Hisaishi dialoga com a direção de Miyazaki.

\section{Resultados e Discussão}

A partir do levantamento bibliográfico e reflexão dos mesmos fez-se evidente a importância do conceito $\mathrm{Ma}$ dentro da obra citada. Este conceito japonês permeia por diversas obras de artistas japoneses e também na sociedade japonesa durante séculos. Não é diferente no caso de Miyazaki; por ele ao dar espaço, importância e utilizar o Ma como um elemento dentro do filme, a articulação do som por sua vez, sofre forte influencia deste conceito.
Miyazaki valoriza o ato de contemplar em seus filmes. Para alcançar este efeito o diretor utiliza diversos recursos, como por exemplo, o recorrente uso de pausas. Por vezes essa pausa ocorre na trilha sonora, simultânea a cenas de muita ação, portanto, sem música ou ruídos fornecendo ritmo e dinâmica. Outras vezes é no campo visual, com uma cena estática ou na narrativa que a pausa ocorre, mesmo havendo trilha sonora nessas cenas.

Para atingir este entendimento foi utilizada a bibliografia referente à teoria do som no cinema, assim se conseguiu uma visão técnica sobre o assunto. No conceito filosófico e estético foi utilizada a bibliografia sobre os poemas japoneses e o conceito Ma. Após isso, foi possível verificar em entrevistas que tanto Miyazaki quanto Hisaishi compartilham de pensamentos artísticos similares, provenientes a cultura japonesa.

\section{Conclusões}

Hoje existem muitas animações no mundo, e em cada produção de cada país é possível destacar praticas e pensamentos artísticos idiossincráticos a sua cultura. Essa pesquisa mostrou que a valorização do espaço temporal potencializa o poder emotivo da trilha sonora, e como consequência o poder emotivo da animação.

Ao utilizar a música com parcimônia dando espaço ao silêncio, a trilha sonora deixa de ser apenas um artifício em prol da dinâmica do filme, e sim passa a ser usada como um elemento narrativo, exprimindo sensações que o dialogo e ou as ações são incapazes de exprimir.

\section{Agradecimentos}

Só foi possível a concretização dessa pesquisa graças ao professor Dr. Ney Carrasco e de igual importância sua doutoranda Carol Leão, que assina comigo como coautora dessa análise.

Gostaria de agradecer as minhas professoras de japonês Ma. Maria Emiko Suzuki, Ma. Ayako Akamine e Bartira Takiuti Ginde que apesar de não ter tido ações diretas nessa pesquisa, foi a partir delas que eu pude ter uma visão menos ocidentalizada e mais sensível à cultura japonesa.

Miyazaki, H. Mononoke Hime. [Princesa Mononoke]. Studio Ghibli 1997 OKANO, M. MA: Entre-Espaço da Comunicação no Japão: um estudo acerca dos diálogos entre Oriente e Ocidente. Pontifícia Universidade Católica de São Paulo. 2007

CARRASCO, N. Trilha Musical: Música e Articulação Fílmica. Universidade de São Paulo, Usp, 1993 